\title{
En el principio era el verbo to be... una mirada etnográfica al inicio del aprendizaje de inglés
}

In the beginning, it was the verb to be... an ethnographic approach to the beginning of English learning

\author{
Eréndira Dolores Camarena Ortiz \\ Universidad Nacional Autónoma de México, \\ Escuela Nacional de Lenguas, Lingüística y Traducción
}

\section{Resumen}

Este artículo es parte de una investigación construyen algunos momentos relevantes, sobre representaciones sociales y creen- situaciones, conflictos y encuentros con cias acerca del aprendizaje del inglés y su otras personas que han influido en su mauso. Se trata de un trabajo de etnografía nera de percibir, sentir y aprender inglés. educativa y de análisis de discurso llevado Al final se hace una breve discusión sobre a cabo con tres grupos de alumnos de la los principales problemas y los aspectos Universidad Autónoma Metropolitana de positivos que han experimentado los alumla Ciudad de México. A través de las na- nos en su trayectoria de aprendizaje de inrraciones de los jóvenes estudiantes se re- glés y que nos ayudan a comprenderlos.

Palabras clave: etnografía educativa; inglés LE; adquisición; creencias; representaciones 


\section{Abstract}

This paper is part of a research on social moments, situations, conflicts, and enrepresentations and beliefs about English counters with other people that have influlearning and its use. It focuses on educaenced their way of perceiving, feeling and tional ethnography and discourse analysis involving three groups of students of the Universidad Autónoma Metropolitana of Mexico City. Descriptions by the young students are used to emulate some relevant learning English. At the end, there is a discussion about the major issues and positive aspects that students have experienced throughout their English learning route, all of which help us to understand them.

Keywords: educational ethnography; English FL; acquisition; beliefs; representations 


\section{Introducción}

Este trabajo es una investigación etnográfica llevada a cabo en la Universidad Autónoma Metropolitana, campus Iztapalapa, de la Ciudad de México. En ella entendemos como relato de vida lingüística la narración que una persona hace acerca de su aprendizaje lingüístico (Fons \& Palou, 2011). En este caso, sobre el inglés como lengua extranjera: la forma como se ha aprendido, el gusto o no por la lengua, las habilidades relacionadas con ella, el uso cotidiano, la identificación como buen o mal aprendiz y las prácticas de los profesores son los temas que de manera inevitable se abordan en estos relatos. Creamos un espacio de confianza para que personas que están involucradas en el proceso de aprendizaje de inglés como lengua extranjera pudieran hablar sobre sus historias y su sentir - como resultado se obtuvieron datos cualitativos muy diferentes a los análisis cuantitativos que se ofrecen en las estadísticas escolares (Ferrarotti, 2007).

\section{Marco teórico}

Serge Moscovici (1979) ha señalado que las representaciones sociales son una modalidad particular del conocimiento, cuya función es la elaboración de los comportamientos y la comunicación entre los individuos. En otras palabras, es el conocimiento de sentido común que tiene como objetivo comunicar, estar al día y sentirse parte del ambiente social, que se origina a partir del intercambio de comunicaciones del grupo social. Por otra parte, Denise Jodelet (2000) postula que el campo de representación designa el saber de sentido común, cuyos contenidos hacen manifiesta la operación de ciertos procesos generativos y funcionales con carácter social, es decir, son una forma de pensamiento social. Robert Farr (1986), por su parte, señala que las representaciones sociales aparecen cuando los individuos debaten temas de interés mutuo o cuando existe la repercusión de los acontecimientos seleccionados como significativos o dignos de interés. No representan simplemente "opiniones acerca de", "imágenes de" o "actitudes hacia" sino teorías o ramas del conocimiento con derechos propios para el descubrimiento y organización de la realidad.

Moscovici (1979) también señala que las representaciones sociales pueden ser analizadas con fines didácticos y empíricos en tres dimensiones: la informa- 
ción, el campo de representación y la actitud. Con este fin, trabajaremos las representaciones como formas de discurso, asumiendo que sus características derivan de las prácticas discursivas de los actores sociales (Villarroel, 2007).

Conceptualmente, Moscovici (1979) expuso que las representaciones sociales son un conjunto de sistemas de creencias, valoraciones y conceptos que se originan, poco a poco, en el intercambio discursivo, conformando un saber común compartido, organizado y jerarquizado por grupos humanos a propósito de un objeto o fenómeno social. La formación de representaciones implica un proceso de socialización mediante el cual se introducen gradualmente maneras de pensar que son típicas de su sociedad. Por esto, consideramos importante que esta investigación indague acerca de lo que alimenta la experiencia de jóvenes estudiantes, con el fin de explorar las representaciones sociales, como las informaciones, conocimientos y modelos de conocimiento que han recibido y que les han transmitido por medio de la educación y las tradiciones (Abric, 2001).

Las creencias como representaciones personales del mundo han sido abordadas por diversas disciplinas humanas como la antropología, la pedagogía, la psicología, etc. En antropología, actualmente las creencias son vistas como preceptos de pensamiento que estructuran la vida de un individuo y que forman parte integral de la cultura (Malinowski, 1985). En el área de pedagogía, Clark y Peterson (1990) las manejan como preconcepciones y teorías implícitas; para Calderhead y Shorrock (1997) las imágenes y creencias de los estudiantes son el producto de sus experiencias individuales pasadas, y Pajares (1992), por su parte, en su artículo sobre creencias de los profesores nos brinda una larga lista de palabras que se han utilizado con el sentido de creencias, tales como: actitudes, valores, juicios, axiomas, opiniones, ideologías, percepciones, preconcepciones, disposiciones, teorías implícitas, teorías explícitas, teorías personales, procesos mentales internos, estrategias de acción, reglas de la práctica, principios prácticos, perspectivas, repertorios de comprensión y estrategia social, todas se refieren a creencias.

En el libro Flatland —Planilandia - (Abbott, 1963 [1884]) se habla acerca de la idea de que nuestra perspectiva en su contexto, que desde el punto de vista de la antropología es parte fundamental de la cultura de un grupo humano determinado, es un elemento que constituye la realidad (Malinowski, 1939). Asimismo, se señala que la determinación de las creencias requiere una varie- 
dad de tipos de evidencia que incluye no sólo lo que el individuo percibe en el discurso, sino también en la conducta de las demás personas.

Las creencias, desde la perspectiva de la enseñanza (Wilson \& Cooney, 2002), son vistas como un constructo que incluye un componente cognitivo y que, pese a tener una condición más débil del saber, se esgrime como conocimiento de algo. Para van Dijk (1996) el conocimiento es una categoría específica de las creencias, es decir, que las consideramos verdaderas de acuerdo a ciertos fundamentos y criterios. Para Calderhead (1996), investigador del ámbito de la psicología educativa, las creencias se refieren a los pensamientos y al entendimiento que un profesor o un alumno tiene sobre la enseñanza y sobre sí mismo.

Los factores que dan forma a nuestras creencias o maneras de pensar derivan de la experiencia: la influencia de la comunidad familiar, escolar, cultural, así como de las características individuales. La influencia familiar se refiere a los modelos que han proporcionado los padres y familiares en casa. La influencia escolar es poner al alumno en contacto con otras comunidades diferentes a la propia, o con instituciones homogéneas que comparten valores entre sí. La influencia cultural incluye todos los rubros anteriores además de los elementos culturales generales que moldean los sistemas básicos de un grupo humano para ver e interpretar el mundo que los rodea. Finalmente, las características individuales se refieren a la manera en que cada individuo se comporta.

Se considera que existen dos funciones de las creencias en el proceso de enseñanza-aprendizaje. La primera está relacionada con las teorías constructivistas del aprendizaje que sugieren que los alumnos entran al aula con creencias ya formadas y que éstas influyen de manera fundamental en qué aprenden y cómo lo hacen. La segunda función apunta a las creencias como el foco de cambio en el proceso educativo. Siguiendo esta línea, las teorías cognitivas más recientes entienden el aprendizaje como un proceso activo y constructivo que está influenciado por la mentalidad, las creencias y las preconcepciones de los individuos (Resnick, 1989). Así, cada profesor tiene su propia visión de cómo aprenden mejor sus alumnos y cómo se puede favorecer y potenciar el aprendizaje en la escuela - a esta perspectiva se le ha denominado "la concepción constructivista de la enseñanza y el aprendizaje escolar" (Coll, Bolea, Colomina Álvarez, De Gispert, Mayordomo, Onrubia Goñi, Rochera \& Segués, 1992: 12). La esencia del constructivismo en la enseñanza es que el individuo no puede conocer 
la realidad como tal, sino que construye modelos de viabilidad para describir el mundo en el que vive.

Las creencias en el aula han sido estudiadas por investigadores como Pajares (1992), Cambra, Civera, Palou, Ballesteros y Riera (2000), Palou (2002), Ramos (2010), entre otros. Estos sistemas que tienen los profesores y los alumnos los ayudan a adaptarse a ambientes nuevos, a definir qué se espera de ellos y a comportarse de acuerdo con estas concepciones (Jimoyiannis \& Komis, 2007). Las expectativas formadas antes de la experiencia, contexto o papel particular también se desarrollan a partir de las creencias. Estas expectativas influyen en la manera como las personas reaccionan, responden y experimentan esa nueva situación. Desde un punto de vista metacognitivo, los conocimientos y las creencias controlan en gran medida la selección, control y monitorización de estrategias requeridas para alcanzar las metas deseadas (Jamissen \& Phelps, 2006).

Con relación a creencias, representaciones y saberes, Devon Woods (1996) realizó un estudio que se centró en los procesos de pensamiento según los cuales algunos profesores de inglés interpretan los eventos en el aula y la información sobre enseñanza y cómo estas interpretaciones influenciaban su planificación y sus prácticas docentes. A partir de esto, Woods propone un constructo hipotético que integra creencias, suposiciones y conocimientos utilizados por los profesores para explicar sus pensamientos y comportamientos - que constituye un modelo etno-cognitivo del proceso de tomas de decisiones- que denomina beliefs, assumptions and knowledge (BAK). Esta noción se caracteriza por la estrecha interrelación de sus elementos y su evolución a través de las experiencias de los profesores como aprendices y docentes. De esta forma, representaciones y creencias son formas de conocimiento individual y colectivo procedentes de distintos niveles de abstracción del significado.

\section{Metodología}

Este estudio retoma el método de dos subdisciplinas: la antropología educativa y la etnografía interpretativa. La primera se entiende como el interés por los procesos educativos, que son a su vez procesos de transmisión de cultura desde una perspectiva holística, su objetivo es la descripción en detalle de las áreas de vida social de la escuela (Woods, 1987), aportando datos descriptivos significativos de 
los contextos, actividades y creencias de los participantes en escenarios formativos para describir las diferentes perspectivas y actividades con el fin de alcanzar explicaciones y revelar patrones de comportamiento (Preissle \& LeCompte, 1984). Por su parte, el método de la etnografía interpretativa requiere escuchar a los participantes, establecer una relación amigable con ellos, preservar sus identidades, desarrollar la investigación en el contexto propio, registrar los datos y analizarlos sin perder de vista los aspectos émico y holístico ${ }^{1}$ (Pujadas, Comas \& Roca, 2004).

La recolección de datos se realizó en el mes de septiembre de 2011, mediante entrevistas individuales semiestructuradas grabadas en la clase inicial del primer trimestre de inglés, dentro del tiempo de la sesión y en presencia del resto del grupo. La sesión se grabó en audio y posteriormente fue transcrita para su análisis. ${ }^{2}$ A continuación se hizo la categorización de temas de acuerdo a los siguientes cuestionamientos: qué se dijo, cómo se dijo y por qué se dijo. Por último, se hizo una breve interpretación. Se trabajó con tres grupos de primer nivel de inglés del Centro de Lenguas de la Universidad Autónoma Metropolitana, campus Iztapalapa. La mayoría de los alumnos son de primer ingreso a la uni-

1 Émico se entiende como un estudio desde el punto de vista del informante y holístico se refiere al estudio de los individuos que intervienen en el proceso educativo y también al contexto educativo, al propio proceso y los componentes que lo integran (Harris, 1979; Pujadas et al., 2004).

2 Nuestra transcripción se ajusta a los criterios de análisis de Palou (2002: 125) y de Cambra (2003: 288-290), que sintetizamos enseguida:

- Se usa letra itálica para las intervenciones verbatim.

- La transcripción mantiene la ortografía convencional.

- Se han utilizado los signos de puntuación usual.

- Las palabras en mayúsculas indican que se enfatiza con volumen más alto de voz.

- Se respetan y registran las pausas que hace la persona que habla.

- No se solucionan las palabras, ni las construcciones gramaticales incorrectas desde el punto de vista de la normativa de la lengua.

- No se apuntan fenómenos relacionados con aspectos fonéticos.

- Se indican los siguientes fenómenos con las marcas indicadas a continuación:

::: alargamiento

(( )) pausa, risa y otros cambios como aumento o baja de volumen de voz

", palabras fuera de la norma o en otro idioma

[] solapamiento o palabras implícitas 
versidad, con edades entre 18 y 24 años. Los grupos de estudiantes son heterogéneos, es decir, provienen de diversas facultades. En total, integran el estudio 58 alumnos del primer nivel de inglés del turno vespertino; 42 mujeres y 16 hombres. En cuanto a los horarios de clase, los alumnos se clasifican del siguiente modo: 31 estudiantes de la clase de 12 a 14 horas, 9 estudiantes de 14 a 16 horas y 18 estudiantes de 16 a 18 horas.

\section{Objetivos}

Los objetivos específicos de este estudio son:

- Analizar los relatos de vida lingüística de los alumnos participantes para profundizar en el examen del repertorio lingüístico y las conexiones que se pueden establecer entre la experiencia, la reflexión y la educación a nivel lingüístico; observando y comprendiendo el proceso de aprendizaje a través de las palabras del alumno, su experiencia individual y la compartida con los demás participantes.

- Destacar en estos relatos qué espacios concretos aparecen — como pueden ser la universidad y la escuela media- y su influencia en los participantes.

- Mostrar qué papel desempeñan factores como el tiempo libre, los medios de comunicación, la diversión, etc., y la influencia que estos ejercen en los entrevistados.

- Explorar las conexiones entre las creencias y percepciones que se manifiestan de manera explícita o implícita en los discursos de los alumnos y las prácticas sociales de referencia, que en este caso son las prácticas educativas, es decir, actividades de aprendizaje con las se logran beneficios tanto para la formación individual como para la comunidad.

\section{Análisis e interpretación de datos}

Las preguntas de la entrevista hechas a los alumnos eran: ¿has estudiado inglés?, ¿te gusta?, ¿por qué te gusta/no te gusta? Los alumnos respondieron a manera de relato libre y pudieron agregar algo más si así lo quisieron. A través del análisis de las respuestas se pudo conocer cómo y dónde fue su estudio del 
inglés y los motivos por los que les agrada o no esta lengua. De esta forma fue posible identificar sus problemas con los métodos de enseñanza, el interés o falta de este por parte de los docentes, la falta de cohesión y coherencia de los programas entre secundaria, preparatoria y universidad, el interés de los jóvenes por la música y otros medios de comunicación que utilizan mayoritariamente el inglés y su visión de la lengua como una herramienta útil y necesaria.

Como hilo conductor, se han buscado referencias a las experiencias que han vivido los estudiantes relacionadas con su entorno escolar y lingüístico; esto con el fin de reconstruir lo que había sido separado en el análisis, reordenándolo en temas para producir un modelo explicativo.

\subsection{Cómo aprendí el inglés que sé}

A continuación se presentan partes de algunas narraciones que nos permiten conocer directamente, con las propias palabras de los participantes, la trayectoria de su aprendizaje del inglés a lo largo de los años. A través de la recurrencia de algunos temas hemos podido reconocer el itinerario seguido por muchos de los alumnos de los tres grupos analizados, los testimonios ofrecen experiencias positivas y negativas, así como sus apreciaciones como aprendientes.

Marcela ${ }^{3}$ es una de las estudiantes que admite haber aprendido (1a), al igual que Dora, quien, de manera pausada y con dudas, finalmente ratifica que llevó un curso de inglés en el que obtuvo ciertos conocimientos (1b).

(1) a. sí, estudié inglés en la prepa, en la secundaria... los dos primeros años... yo pienso que aprendí más porque la escuela era más a nivel internacional. [Marcela, C 12-14]

b. de inglés de la secundaria; eh:: prepa y:: este:: un tiempo estuve, bueno. Un tiempo que estudié un nivel, nada más en-en UPIICSA. Pero sí tengo [bastante... Profesora: ¿en el Poli?]. [Dora, C 12-14]

3 Todos los nombres son pseudónimos. Al final de cada testimonio se brinda, además del pseudónimo, una etiqueta de identificación que indica el horario de la clase del alumno. 
Dos alumnas apuntan a profesores deficientes, por ejemplo, Ana Karen (2a) expresa que en la secundaria solamente llevó un año la clase de inglés y justifica que fue por falta de maestros, así como en la preparatoria. Este caso es similar al de Marisol (2b), ambos testimonios nos muestran una falta de formalidad en la enseñanza de lenguas extranjeras.

(2) a. Y en la prepa, pero el maestro casi no... asistía. [Ana Karen, C 12-14]

b. ((voz muy baja)) estaba, estaba muy mal ((sube el volumen)) con los profesores... Continúa relatando: el inglés [lo llevé] en la secundaria. Estaba, estaba muy mal ((sube el volumen)) CON LOS PROFESORES. Aparte 'namás' tenía UN profesor que daba todas las materias. [Marisol, C 12-14]

Marisol explica que al igual que sus compañeros llevó inglés en la escuela secundaria, pero que no aprendió (3a). De igual manera Samuel, quien describe en (3b) su situación, y cuyo tono de voz también da a entender que aprendió muy poco. También Adriana, por su parte, dice no tener conocimientos (3c).

(3) a. y pues este, no::, igual que todos ((tono de queja)). El inglés en la [secundaria... ((pausa)) Profesora: ¿el desastre?]. [Marisol, C 12-14]

b. el inglés sólo lo llevé en los tres años de secundaria y en preparatoria un año. [Samuel, C 12-14]

c. bueno, sólo lo que me han enseñado en la secundaria... preparatoria. [Adriana, C 12-14]

Otros dos alumnos nos informan que el aprendizaje del inglés es un tema aburrido. Benjamín (4a) nos da el alarmante dato sobre el número de años de estudio en los que ha aprendido poco. Berenice lo corrobora en (4b). Así vemos que la materia de inglés para algunos estudiantes es vista como algo fastidioso.

(4) a. en los seis años que llevé inglés, sólo te aburren... [Benjamín, C 12-14]

b. mis clases han sido muy terribles, porque siento que es muy tedioso. [Berenice, C 12-14] 
Citlali, alumna de otra clase, nos da un breve panorama explicando qué sucede con el inglés como materia escolar (5).

(5) ¿por qué tal vez no le tomo mucho interés...? Lo que pasa es que el inglés siempre ha sido como el "patito feo" ¿no? La-la materia que queda así, como por fuera... Pero ahora como ya es curricular, pues ahora sí hay que estudiar ¿eh? ((risas)). [Citlali, C 14-16]

La frase queda por fuera nos dice que se le daba poca validez al inglés como parte de los estudios, no se respetaba la materia, los alumnos simplemente la asumían y la toleraban, hasta que se volvió curricular. La alumna la define metafóricamente como el patito feo, expresión que utiliza para ejemplificar que al principio no se le tomaba en consideración, pero que después se hizo importante.

Para otro alumno, Israel, el inglés era un asunto de indagación (6), describe la lengua como un arma positiva, calificada de elemental, para referirse a su vital importancia.

(6) desde pequeño siempre hubo como una inquietud, hacia lo que era:::, y curiosidad pues hacia lo que era al idioma inglés. Y también para aprenderlo. Este::: eh::, y 'pus' ya a lo largo, del tiempo también me di cuenta que era una de las herramientas que:: pues sí elementales. [Israel, C 16-18]

\subsubsection{Síntesis}

El tema principal en estas narrativas es el proceso de aprendizaje de inglés. Se identifica el itinerario con el que los alumnos toman conciencia de lo que saben y hacen con la lengua que conocen. Así, en los relatos podemos ver que la mayoría inició su instrucción en la adolescencia y continuó con ella hasta ser jóvenes adultos universitarios. Las palabras clave de esta parte son secundaria y prepa, donde estudiaron lo básico. También podemos observar las situaciones por las que han pasado los alumnos en su aprendizaje de inglés cuando utilizan verbos declarativos llevé, tuve, siento y estudié, orientados a la descripción y que se articulan como parte de su proceso educativo. El inglés es calificado como tedioso, molesto, patito feo, pero también como una útil herramienta. Hablan en un 
tono informal y la intensidad de la voz de algunos de ellos nos indica emociones negativas y positivas acerca de su iniciación al estudio de esta lengua extranjera, como, por ejemplo, afirma una estudiante: es una materia ya obligatoria, ya dice que como que a fuerzas lo tienes que aprender ((tono de queja)) y como que jay! No [Mariana, C 14-16]. La prosodia o conjunto de fenómenos fónicos como entonación, acentuación, ritmo, velocidad, cumplieron una función clave en la organización e interpretación de su discurso y, además, transmiten información emotiva y sociolingüística. Por ejemplo, un alumno dice: estuve en ((voz muy baja hasta aquí, y luego sube el volumen y aumenta la velocidad)) nivel intermedio, PERO, no hay nada como que valide aquí en la universidad [Rodolfo, C 12-14]. En cuanto a sus apreciaciones cualitativas tenemos expresiones de varios estudiantes que califican al inglés como aburrido y pesado, pero también tenemos palabras significativas como curiosidad y herramienta. Con relación al paralenguaje, uno de los elementos que se utiliza más es la risa, que más que alegría demuestra nerviosismo y vergüenza por ciertas situaciones, como, por ejemplo: no voy a decir que no la he llevado [la gramática del inglés] así ((risas)), pero se me olvida [Marisol, C 12-14].

\subsection{Por qué no me gusta el inglés}

En esta sección se narran algunas de las situaciones que han representado para los alumnos problemas en el aprendizaje de la lengua y que han sido determinantes para que este proceso no sea de su agrado. Estas narraciones nos aportan un valor añadido al ser apuntados con una gran fuerza expresiva por parte de los participantes.

Una alumna, Isela, reconoce que necesita aprender inglés y lo asume (7a), a pesar de eso, explica que no es de su gusto (7b).

(7) a. yo estoy aquí porque ahorita en este momento nos tocó, estoy intentando [leer] artículos que están en inglés.

b. y desafortunadamente a no me::, a mí no me gusta el inglés y quiero encontrarle-encontrarle::: Profesora: el gusto... Isela: la razón. [Isela, C 12-14] 
Otra cuestión son los estudiantes que tienen dificultades para aprenderlo, lo que indica una didáctica poco adecuada en su anterior proceso de aprendizaje. Tal es el caso de Beatriz, quien afirma que el aprendizaje de inglés es difícil para ella (8a). Cristina, por su parte, explica sus dificultades específicas (8b). Y, por último, Mariana justifica su poco conocimiento de inglés (8c).

(8) a. pero a mí sí se-se me dificulta mucho, la verdad ((risas en voz muy baja)) y argumenta: y no entiendo nada ((risas en voz muy baja)). [Beatriz, C 12-14]

b. eh:: lo que más se me dificulta es la pronunciación. Casi tam-tampoco me gusta ((voz muy baja)). [Cristina, C 12-14]

c. lo:: que no me gusta, es que se me hace muy complicado, especialmente cuando uno habla, pues lo hacen muy rápido... Las palabras se me olvidan fácilmente y algunas estructuras las confundo por otras. Y::: también se me olvidan. [Mariana, C 12-14]

En estos comentarios, se presenta un lenguaje conflictivo donde abundan risas, titubeos y palabras negativas con relación al aprendizaje de la lengua. Esto nos lleva a pensar que son relatos sintomáticos que demuestran que la pronunciación constituye un fondo de dudas.

Tania describe también métodos de enseñanza desfavorables en (9). La alumna revela un recurso tecnológico ingenioso que utilizaba para sortear las traducciones y ejercicios repetitivos que le pedían, pero de los cuales no obtenía ningún conocimiento.

(9) me ponían a hacer nada más puras oraciones, puras oraciones... y a traducir puros textos. Y pues:: se me hacía más fácil ir a internet y traducirlos ((risas del grupo)), que estar haciéndolos. Profesora: ((risas)) ¡los sacabas con el traductor [de google! Tania: sí] me aburría, y 'pus' los maestros al ver la esa:: ya traducida, pensaban que uno lo había hecho... [Tania, C 12-14]

El alumno Omar también habla de las contrariedades que tiene con el inglés, pero no explica por qué no le agrada e incluso afirma que tampoco le gusta su lengua materna, como puede observarse en el diálogo de (10). 
(10) Omar: nada más que:: no me gusta porque 'ps' no se me da, se me hace muy difícil. Profesora: ¿y por qué no se te da?, ¿eh?

Omar: 'ps' tampoco me gusta el español.

Profesora: ((risas de ella y de otros alumnos)) ipero sí lo hablas!

Omar: 'ps' ya qué... ((risas)). [Omar, C 14-16]

A Jessica tampoco le agrada el inglés (11a). Considera el estudio del inglés como una exigencia desagradable, aunque quisiera saber analizarlo. Por otro lado, Anayelli (11b) apunta de nueva cuenta al problema del estudio del inglés a través de la gramática y también se queja de la pronunciación, dificultad que quizás ha sido poco estudiada en el entorno de la educación media, pero que se menciona a menudo en estos grupos como un fuerte impedimento.

(11) a. bueno a mí en realidad no me gusta. Lo tengo que estudiar también porque es obligatorio para la carrera y también porque como::: lengua, es-lo podría utilizar como para análisis de una lengua. [Jessica, C 14-16]

b. este:: y no me gusta [el inglés] porque soy mala en la gramática y en la pronunciación. [Anayelli, C 14-16]

Siguiendo esta línea, Karen afirma que no le agrada el inglés y argumenta que le es difícil aprender las reglas para hablar y escribirlo correctamente (12a). Para Sheila el aprendizaje del inglés se ha limitado igualmente a las normas, por lo que no ha podido asimilar cómo usar la lengua en la vida real (12b). En ambos casos podemos notar el rechazo hacia las metodologías de enseñanza del inglés, que se emplean sin ninguna aplicación, competencia comunicativa o reflexión.

(12) a. y no me gusta porque me cuesta un poco aprenderlo ((voces de los compañeros comentando y riéndose)). Profesora: ¿y por qué te cuesta aprenderlo? Karen: ahm:::, por:: por más que nada la gramática. [Karen, C 16-18]

b. este:: y no me gusta porque se me hace un poco técnico, porque::, bueno, así a como me lo han enseñado... pues, así como que nada más se enfocan en reglas, reglas, reglas... pero no:: Profesora: ¿nada de uso? [Sheila, C 16-18] 
Por su parte, Yariela explica que le confunde la polisemia de algunas palabras (13a), a lo que la profesora argumenta que ese fenómeno existe también en el español y en todas las otras lenguas. Abraham también describe otro problema específico (13b), que es la similitud entre palabras, pero no termina de expresar exactamente qué le causa problemas.

(13) a. este::, no me gusta porque:: a veces es confuso. Tiene palabras que::, bueno por ejemplo una palabra para referirse a dos cosas distintas. [Yariela, C 16-18]

b. y:: no me gusta porque hay cosas que... se parecen mucho y me revuelvo y::, igual al leerlo no... [Abraham, C 16-18]

Mientras, Sheila, que ha estado atenta a la participación de sus compañeros, concuerda con esas opiniones, emitiendo una expresión afirmativa: ajá... Finalmente, Susana también afirma que no le agrada el inglés porque es pesada la pronunciación y da otra razón de peso que es importante: la pena que siente al hablar otra lengua, lo cual otros compañeros también mencionaron (14).

(14) $y:::$ no me gusta porque:: me parece difícil la pronunciación... y me da vergüenza ((risas)). [Susana, C 16-18]

\subsubsection{Síntesis}

Una lectura del conjunto de estas breves historias nos ofrece algunas pinceladas e imágenes del espacio vivido por estos alumnos con relación a la lengua, la escuela. Además de lo que se hace en el salón de clases, hay muy poca o ninguna otra vinculación con el uso real del inglés, salvo con la música. Esto conlleva riesgos de distancia, desánimo y falta de interés por la lengua. La frase clave fue no me gusta. Las repetidas negaciones nos demuestran diversas situaciones adversas que han afectado el aprendizaje. Se hace evidente lo repetitivo de los programas y ejercicios, sobre todo de verbos — de ahí el título de nuestro artículo-, y lo poco que ha agradado a los alumnos. Esto se constata en frases como: pues básicamente es lo mismo, lo mismo [Marcela, C 12-14]; se me hace muy repetitivo y constante [Emanuel, C 16-18]. Y en comentarios como los que se citan a continuación. 
(15) a. llevé inglés 'namás' en la secundaria y en la prepa. Pero pues igual, lo básico ¿no? El verbo ‘to be’ ¿no? ((risas)). Sí, sí, los CINCO años ¿eh? [...] [Sandra, C 12-14]

b. sólo te aburren haciendo planillas y planillas de verbos, que ni siquiera te dicen su traducción al español, sólo te mandan hacerlo. Y por el verbo 'to be' ((risas)) [...] [Sandra, C 12-14]

Encontramos también la percepción de algunos estudiantes de que el inglés es difícil (16a), como se ilustra en los siguientes comentarios. Algunas alumnas establecen la pronunciación como un obstáculo (16b); también observamos problemas con el aprendizaje de la gramática (16c).

(16) a. no le hallo pasión, quiero encontrarle la razón, se me hace complicado. [Alui, C 12-14]

b. soy mala en la pronunciación. [Stephanie, C 16-18]

c. confundo la conjugación de los verbos; lo que a mí se dificulta es 'grammar', se enfocan en reglas, reglas, reglas..., soy mala en la gramática. [Alejandra, C 12-14]

En resumen, se observan cuatro problemas básicos: lo repetitivo de los programas, las dificultades con una pronunciación ajena a su sistema lingüístico, el aprendizaje monótono de reglas gramaticales y la falta de uso real de la lengua inglesa. También observamos muchos alargamientos y pausas que nos muestran parte de lo no dicho. El silencio es la expresión discursiva más clara para describir la frustración que surgió como resultado de esas clases poco exitosas, que no han generado condiciones para el uso de la lengua. Hay varias risas nerviosas en las opiniones negativas expresadas por algunos participantes al dar información controversial, que de alguna manera pone en peligro su imagen como estudiantes. Los alumnos también usan la risa para atenuar, pues demuestran estar apenados por lo que ha sucedido con su aprendizaje de inglés y en ocasiones parece que se sienten un poco culpables por la situación generada. 


\subsection{Por qué sí me gusta el inglés}

En esta sección analizamos los elementos positivos con relación al aprendizaje del inglés. Los participantes hacen uso de la ejemplificación para argumentar las razones por las cuales el inglés sí es de su agrado, además de ser necesario para su carrera. Exponen progresivamente los beneficios de aprender la lengua y la vislumbran como una herramienta útil en los proyectos de vida que están iniciando.

Sandra apunta la exigencia de estudiar inglés como requerimiento para los estudios y argumenta el interés propio (17a). Berenice, por su parte, alude las mismas razones (17b). Del mismo modo opina Claudia (17c), quien reconoce que muchos de los textos académicos están escritos en esta lengua.

(17) a. y aparte de que lo necesito para mi carrera, también me interesa, estudiarlo como personal. [Sandra, C 12-14]

b. y me gusta porque 'pus' ahora es indispensable para llevar una vida profesional. [Berenice, C 12-14]

c. a mí me gusta porque va a ser necesario para mi carrera, por los libros que ya casi todos son en inglés. [Claudia, C 12-14]

Por otro lado, Marisol explica que para ella el vocabulario es fácil de aprender (18a). Y Samuel recurre a una expresión popular para decir que tiene un cierto nivel de la lengua (18b).

(18) a. se me facilitan mucho los significados, esos sí me los aprendo fácilmente. [Marisol, C 12-14]

b. por 'ai', más o menos 'ai dos-tres'. [Samuel, C 12-14]

Algunos estudiantes comentan su gusto por el inglés a través de la música, como Alejandra (19a), Luis (19b) y Mariana, quien además enfatiza su deseo de viajar (19c).

(19) a. pues:: a mí me gusta, pues nada más escucharlo en algunas canciones. [Alejandra, C 12-14] 
b. me gusta::, porque:: más que nada me gusta mucho la música, y porque es indispensable para mi carrera. [Luis, C 12-14]

c. bueno, yo le puse que me gusta el inglés, por las canciones::, y porque yo siempre he querido viajar a Inglaterra y:: para ir hasta allá, es necesario aprender el idioma. [Mariana, C 12-14]

Para Janet el inglés es una materia asequible (20a); para Jessica, una manera de acceder a los temas de cómputo (20b); por su parte, Nayelli argumenta que es una necesidad y un gusto (20c), y para Anayelli es una forma de comunicación (20d). Por último, para Karen es una herramienta beneficiosa que no evade (20e).

(20) a. bueno, pues:: a mí, 'pus' no sé si me gusta..., pero yo siento que se me hace fácil; igual ((volumen bajo)), al principio en la secundaria era pésima, luego me metieron así como a un curso de verano, y en la prepa ya sabía..., bueno, como ya 'le agarraba más la onda' al inglés. Y pues de ahí como que ya me gustó porque como que vi que era fácil. [Janet, C 14-16]

b. a mí se me hace interesante y::, por lo referente a los programas de computación... [Jessica, C 14-16]

c. siento que ahora ya es un::, idioma muy básico para cualquier carrera. Ehm::: también me gusta mucho la música inglés; me gusta cómo se escucha. [Nayelli, C 14-16]

d. y a mí me gusta el inglés porque siento que es otra forma de-para poder comunicarnos con las personas. [Anayelli, C 14-16]

e. me gusta porque es:: un idioma importante y demasiado útil para... para mi carrera. [Karen, C 16-18]

En otros casos, como el de Rebeca, hay un gusto por la pronunciación (21a); Sheila, por su parte, explica que le gusta y que además es un medio de acceso a otras culturas (21b). Del mismo modo, Susana reconoce el inglés como la lingua franca (21c) y Christian lo requiere como medio de entendimiento (21d).

(21) a. y:: me gusta porque también, bueno, me gusta cómo suena; y por ejemplo en el::, de Inglaterra, me gusta mucho su acento. [Rebeca, C 16-18] 
b. me agrada, porque puedo cono-conocer diversas culturas, este objetos que a la vez este, no me permite conocerlo mediante el español. [Sheila, C 16-18]

c. es necesario [el inglés] para poder comunicarnos no solo con personas de habla inglesa sino con todo el mundo. [Susana, C 16-18]

d. para entender la música, o las mismas cosas que salen en la televisión. [Christian, C 16-18]

\subsubsection{Síntesis}

Como los relatos de vida lingüística ofrecen un marco idóneo para reflexionar y aprender de la propia experiencia, en este estudio se pone también de manifiesto el valor del aprendizaje de una lengua extranjera como es el inglés. Dada la naturaleza de las preguntas, los alumnos se refieren mayormente a yo y a mí, y en esta parte predomina el verbo me gusta, palabras con las que expresan diversas apreciaciones sobre esta lengua. Dentro de la experiencia compartida en diferentes entornos y episodios del aprendizaje del inglés los comentarios coinciden en algo importante, la necesidad de esta lengua para el desarrollo de su vida profesional. Los comentarios (22a-b) ejemplifican el tema. Otros alumnos reconocen en el inglés una fuente de oportunidades laborales (22c-d). Sin embargo, algunos afirmaron que no les gusta.

(22) a. aparte de que lo necesito para mi carrera, también me interesa; como que-que necesito aprenderlo, porque es algo indispensable para, poder desempeñar no sé, mi carrera; y me gusta porque 'pus' ahora es indispensable para llevar una vida profesional. [Sandra, C 12-14]

b. a mí me gusta porque va a ser necesario para mi carrera, por los libros que ya casi todos son en inglés. [Claudia, C 12-14]

c. es la lengua que abre más puertas... de empleo; es un idioma importante... puedo tener más oportunidades de trabajo. [Iván, C 16-18]

d. porque, te abre muchas oportunidades. [Jorge, C 12-14]

Otra de las razones más recurrentes por la que los alumnos desean aprender inglés es por su interés en la música actual y la televisión (23a-b). 
(23) a. pues a mí me gusta, pues nada más escucharlo en algunas canciones. este, pues es que me gusta el inglés, por las canciones; me gusta porque más que [Alejandra, C 12-14]

b. nada me gusta mucho la música; por las canciones que o sea es, saber lo que dicen. [Alejandra, C 12-14]

También lo ven como una oportunidad de conocimiento, es decir, como un medio tanto de comunicación (24a) como para conocer a otros individuos (24b) y otras culturas (24c), reconociendo su papel relevante a nivel internacional (24d). Relataron que quieren viajar, estudiar en el extranjero, conocer otras culturas y a otras personas.

(24) a. y a mí me gusta el inglés porque siento que es otra forma de-para poder comunicarnos con las personas; me gusta porque rompe barreras de comunicación. [Anayelli, C 14-16]

b. para relacionarme con más personas. [Jorge, C 12-14]

c. y porque puedes conocer costumbres y tradiciones de otros países; el inglés me agrada, porque puedo conocer diversas culturas, este objetos que a la vez este, no me permite conocerlo mediante el español; quiero conocer el inglés, es porque me emociona este, así como saber el idioma, bueno y ahí como dicen las lenguas que, los países que lo hablan. [Susana, C 16-18]

d. y también porque es necesario para poder comunicarnos no solo con personas de habla inglesa sino con todo el mundo; en la actualidad tiene una importancia a nivel internacional. [Susana, C 16-18]

Por último, los alumnos admiten el estudio del inglés como un objeto y una herramienta de estudio (25a-b).

(25) a. lo podría utilizar como para análisis de una lengua, yo estoy estudiando lingüística; pienso que es interesante manejar y conocer la estructura del idioma. [Jessica J., C 14-16]

b. por lo referente a los programas de computación, a mí me gusta. [Jessica R., C 14-16] 


\subsection{Los docentes}

Por otro lado, los alumnos también mencionan a las personas que hicieron una diferencia positiva en el aprendizaje de inglés. Una estudiante habla de lo beneficioso que le resultó tener actividades reales con la lengua extranjera (26a), otra alumna relata que el profesor les daba actividades interesantes y en grupo, que no eran repetitivas o mecánicas (26b), además hablan de otras situaciones que facilitaron su introducción a la lengua extranjera como los cursos extraescolares (26c).

(26) a. sí me gusta, porque, bueno, ya la 'teacher' que tuve en la prepa ya en mi último año, nos mandó al Museo de Antropología y ahí a las personas extranjeras que venían, les hicimos una entrevista. Y pues desde ahí me gustó, porque se me hizo interesante.

b. a mí me gusta el inglés, considero, no sé si por el maestro que tuve, pero considero que es fácil de aprender; me agradaba porque él, eh, no era un hombre que nos pusiera a hacer planas, como algunos compañeros les llaman. Era más de trabajos didácticos, a veces en equipo.

c. al principio en la secundaria era pésima, luego me metieron así como a un curso de verano, y en la prepa ya sabía, bueno, como ya le agarraba más la onda al inglés. Y pues de ahí como que ya me gustó porque como que vi que era fácil.

Hoy sabemos que el papel de los formadores, además de enseñar un conjunto de conocimientos, es ayudar a los estudiantes a "aprender a aprender" y promover su desarrollo cognitivo y personal. Esto sería posible mediante actividades aplicativas y críticas que tengan en cuenta sus características personales, aprovechando la inmensa información disponible. Además, sería pertinente exigir un procesamiento activo e interdisciplinario de la lengua para construir su propio conocimiento y no limitarse a realizar una simple recepción pasiva de la información o simplemente memorizarla.

\section{Discusión}

Cualquier experiencia de vida encierra en sí una dimensión social. A través de la actividad lingüística en el ámbito escolar y social, pudimos vislumbrar algu- 
nos aspectos sobre los comportamientos de los estudiantes y sus expectativas, y deseamos poner toda esta experiencia al servicio de los docentes. Es necesario recordar la importancia de investigar la historia del alumnado, sobre todo escuchar sus voces, para comprender sus situaciones e implementar estrategias que posibiliten el aprendizaje. Desde este punto de vista nuestra perspectiva constituye también una forma innovadora de aproximarnos a la realidad escolar.

Estas breves historias de vida lingüística nos han permitido explorar un tipo de datos específico y construir un campo de estudio a partir de una situación de aprendizaje escolar. El objetivo es escuchar las diversas voces de los participantes a fin de introducir cambios en la enseñanza de lenguas extranjeras con base en un corpus de datos específico sobre la experiencia de aprendizaje en la escuela y la práctica de enseñanza-aprendizaje, donde lo personal pasa a ocupar una parte fundamental del territorio de la educación, ya que lo personal y lo social están profundamente vinculados al aprendizaje (Hernández, 2011: 13-14).

Como un breve resumen de resultados, queremos apuntar en primer lugar que a los jóvenes participantes no les causó ningún problema involucrarse en la entrevista y respondieron de forma positiva a la petición de expresar sus experiencias e inquietudes. Con esto pudimos vislumbrar que es posible hablar sinceramente con los alumnos y que podemos contar con su colaboración.

Una constante que pudimos apreciar en este estudio es un problema de vínculo entre la escuela media y la universidad, ya que al parecer los programas de secundaria y preparatoria no se ajustan a las expectativas de la educación superior. Además de estos desencuentros que pertenecen al campo de las políticas educativas nacionales, se advierte también un desajuste originado por las diferencias de creencias y representaciones entre alumnos y profesores; las primeras ocurren en un nivel personal y las segundas, en un nivel social. Riley (1989) parte de la hipótesis de que el aprendizaje de una lengua dependerá en parte de las creencias y representaciones que el aprendiente tenga sobre la situación educativa. Los resultados de algunas investigaciones han probado que las creencias son factores determinantes en el éxito o fracaso del estudiante dependiendo de la experiencia que haya tenido con la lengua. Desde las creencias, la lengua es aparentemente para algunos profesores - de acuerdo con los relatos de los estudiantes - un sistema gramatical, un programa que cumplir, un libro que terminar, un ejercicio que llenar, un horario que cubrir. No obstan- 
te, también se habla de docentes que hicieron una diferencia y que están conscientes de que la lengua es un sistema de comunicación que puede ser interesante y divertido de aprender.

Si bien el inglés puede ser una herramienta, un instrumento, un arma o un medio de comunicación y diversión para los estudiantes, también puede ser una molestia, un tema aburrido, repetitivo o tedioso. Por esta razón, es importante subrayar el hecho de que una lengua tiene representaciones y significados diferentes para cada grupo humano (Pozzo \& Soloviev, 2011) y, en este sentido, examinar lo que representa para estos participantes: una necesidad en la vida actual, una ventana a otra cultura, una herramienta de trabajo o literatura, una posibilidad de becas y mejores empleos y, al mismo tiempo, una imposición, un reflejo de relaciones colonialistas o motivo de descontento. De esta manera, la lengua inglesa es considerada por estos alumnos como algo ajeno o lejano de su realidad, excepto cuando se emplea para la música, la red y los juegos.

Asimismo, se puso de manifiesto la poca importancia que se le da a las lenguas extranjeras en el sistema educativo nacional. También se hizo evidente un fallo metodológico que marca el proceso de enseñanza-aprendizaje del inglés, lo que nos convoca a la necesidad de darle un enfoque diferente a este proceso. Aparentemente no se reconocen las diferencias entre la eficacia y la eficiencia: la primera logra su objetivo, pero la segunda lo logra de la mejor manera posible. De esta manera, al realizar repeticiones los alumnos probablemente lograrán aprender el verbo to be, y eso puede resultar eficaz. Sin embargo, al no saber para qué lo memorizan o cómo se usa, no resulta una tarea eficiente. Por esta razón, los alumnos generalmente pierden interés por aprender una lengua extranjera. Por otro lado, los alumnos expresaron un temor hacia la lengua, en el sentido de no entender, no hacerlo bien o no pronunciar correctamente. Las personas que aparecen asociadas al inglés en general son docentes, quienes, de acuerdo con los testimonios de los alumnos, tampoco parecen darle importancia al problema de la escasa relevancia que tienen las lenguas extranjeras dentro de los planes y programas de estudio en cuanto a la calidad y constancia de su enseñanza. Cuestión que se refleja en el bajo rendimiento estudiantil en el aprendizaje de inglés.

Aunque no todas las creencias y representaciones son compartidas, hay trazos comunes en estas historias de vida linguiística que nos ayudaron mucho 
a comprender en parte algunos procesos de cambio que los alumnos como jóvenes adultos están experimentando (Bertaux, 2005: 105). Pudimos notar que prevalece una noción negativa sobre las metodologías de enseñanza-aprendizaje y, al mismo tiempo, una concientización sobre la necesidad que tienen de la lengua, especialmente por los ritmos acelerados con los que se produce la llegada a la universidad y por la rapidez en la transmisión de las consecuencias de esta circunstancia. Así, podemos ver que el inglés se ha convertido en un problema para muchos y que es un tema que afecta su desempeño escolar en general. Por el ambiente actual de uso generalizado de internet, los estudiantes están convencidos de que deben estudiar la lengua inglesa, pero generalmente no es una decisión por gusto. Por otro lado, tampoco han establecido relaciones positivas con el aprendizaje formal de la lengua, además de "pasar la materia", aunque prevén obtener beneficios de su aprendizaje como becas, mejores empleos, viajes, etcétera.

En las historias de los alumnos las representaciones no se presentan solas, sino en relación con personas, como son los profesores, y con objetos, como los programas de estudio, la metodología de la enseñanza y las clases de inglés en la educación media. No se aprecian muchas experiencias de uso real con la lengua, ni tampoco autonomía como parte del aprendizaje. Percibimos asimismo competencias insuficientes de alfabetización funcional: es decir, la materia no guarda relación definida inmediata con las necesidades colectivas, ni con las individuales. Inferimos que los administradores de la educación media y del sistema educativo nacional toman ciertas decisiones sin tener conocimiento sobre lo que pasa realmente en el aula. En resumen, creemos que se debe enseñar el uso de la lengua intentando coligar los niveles de enseñanza para evitar caer en las repeticiones de año tras año y crear oportunidades de uso de la lengua, además de enseñar gramática en contexto y abordar temas que sean de interés para los jóvenes. 


\section{Referencias}

Аввотт, Edwin (1963 [1884]). Flatland: A romance of many dimensions. Nueva York: Barnes \& Noble.

Abric, Jean-Claude (2001). Las representaciones sociales: aspectos teóricos. En Jean-Claude Abric (Dir.), Prácticas sociales y representaciones (pp. 11-32). México: Ediciones Coyoacán. Bertaux, DANiel (2005). Los relatos de vida: perspectiva etnosociológica. Barcelona: Bellaterra.

Calderhead, James (1996). Teachers: Beliefs and knowledge. En David Berliner \& Robert Calfee (Eds.), Handbook of educational psychology (pp. 709-725). Nueva York: Macmillan.

Calderhead, James, \& Shorrock, Susan (1997). Understanding teacher education: Case studies in the professional development of beginning teachers. Londres: Falmer Press.

CAmbra Giné, Margarida (2003). Une approche ethnographique de la classe de langue. París: Didier.

Cambra Giné, Margarida; Civera, Isabela; Palou Sangrá, Juli; Ballesteros, Cristina, \& Riera Figueras, Montserrat (2000). Creencias y saberes de los profesores en torno a la enseñanza de la lengua oral. Cultura y Educación, (17-18), 25-40.

Clark, Cristopher, \& Peterson, Penelope (1990). Procesos de pensamiento de los docentes. En Merlin Wittrock (Comp.), La investigación de la enseñanza, III: profesores y alumnos (pp. 443-539). Barcelona: Paidós.

Coll, César; Bolea, Enric; Colomina Álvarez, Rosa; De Gispert, Inés; Mayordomo, Rosa; Onrubia Goñi, Javier; Rochera, José, \& Segués, María Teresa (1992). Interacció, influència educativa i formes d'organització de l'activitat conjunta. Temps d'Educació, (7), 11-87.

FARR, RoBert (1986). Escuelas europeas de psicología social: la investigación de representaciones sociales en Francia. Revista Mexicana de Sociología, 45, 641-657.

Ferrarotti, Franco (2007). Las historias de vida como método. Convergencia. Revista de Ciencias Sociales, (44), 15-40.

Fons, Montserrat, \& Palou, Juli (2011). Els relatats de vida lingüística en els processos de formació dels docents. En Fernando Hernández, Juana María Sancho \& José Ignacio Rivas (Coords.), Historias de vida en educación: biografías en contexto (Esbrina 4, pp. 108-115). Barcelona: Universitat de Barcelona. Recuperado de http://hdl.handle.net/2445/15323

Gumperz, John, \& Hymes, Dell (Eds.) (1972). Directions in sociolinguistics: The ethnography of communication. Nueva York: Holt, Rinehart \& Winston.

HARris, MARVIN (1979). El materialismo cultural. Madrid: Alianza. 
Hernández, Fernando (2011). Las historias de vida en el marco del giro narrativo en la investigación en Ciencias Sociales: los desafíos de poner biografías en contexto. En Fernando Hernández, Juana María Sancho \& José Ignacio Rivas (Coords.), Historias de vida en educación: biografías en contexto (Esbrina 4, pp. 13-22). Barcelona: Universitat de Barcelona. Recuperado de http://hdl.handle.net/2445/15323

Jamissen, Grete, \& Phelps, Renata (2006). The role of reflection and mentoring in ict teacher professional development: Dialogue and learning across the hemispheres. Teacher Development, 10(3), 293-312.

Jimoyiannis, Athanassios, \& Komis, VassiLis (2007). Examining teachers' beliefs about ICT in education: Implications of a teacher preparation programme. Teacher Development, 11(2), 149-173.

JODELET, DENISE (2000). Representaciones sociales: contribución a un saber sociocultural sin fronteras. En Denise Jodelet \& Alfredo Guerrero (Coords.), Develando la cultura: estudios en representaciones sociales (pp. 7-30). México: Facultad de Psicología, Universidad Nacional Autónoma de México.

Malinowski, Bronislaw (1939). The group and the individual in functional analysis. American Journal of Sociology, 44(6), 938-964. Recuperado de https://pdfs.semanticscholar. org/84c4/6621a71ee9f11500c93fa31c37a0c070dcc7.pdf

Malinowski, Bronislaw (1985). Magia, ciencia y religión. México: Origen/Planeta.

Moscovici, Serge (1979). El psicoanálisis: su imagen y su público. Buenos Aires: Huemul.

PAJARES, Frank (1992). Teachers' beliefs and educational research: Cleaning up a messy construct. Review of Educational Research, 62(3), 307-332.

Palou, Juli (2002). L'ensenyament i l'aprenentatge del català com a primera llengua a l'escola. Creences i actuacions dels mestres amb relació a les activitats de llengua oral a l'etapa de primària (Tesis doctoral inédita). Universitat de Barcelona, Barcelona.

Pozzo, Isabel, \& Soloviev, Konstantin (2011). Culturas y lenguas: la impronta cultural en la interpretación lingüística. Tiempo de Educar, 12(24), 171-205. Recuperado de http://www. redalyc.org/pdf/311/31121089002.pdf

Preissle, Judith, \& LeCompte, Margaret (1984). Ethnography and qualitative design in educational research. Orlando: Academic Press.

Pujadas, Joan; Comas, Dolors, \& Roca, Jordi (2004). Etnografía. Barcelona: Universitat Oberta de Catalunya. 
RAMOS, CARMEN (2010). Las creencias de los alumnos: posibles implicaciones para el aula de español como lengua extranjera. MarcoELE. Revista de Didáctica Español Lengua Extranjera, 10, 105-116. Recuperado de marcoele.com/descargas/expolingua_2006.ramos.pdf

RESNiCK, LAUREN (1989). Introduction. En Lauren Resnick (Ed.), Knowing, learning and instruction: Essays in honor of Robert Glaser (pp. 1-14). Hillsdale: Lawrence Erlbaum.

Riley, PhiliP (1989). Learners' representations of language and language learning. En Centre de Recherches et d'Applications Pedagogiques en Langues (Ed.), Mélanges Pédagogiques 1989 (pp. 65-72). Nancy: Centre de Recherches et d'Applications Pedagogiques en Langues, Université de Nancy II.

van DiJk, Teun (Ed.) (1996). Handbook of discourse analysis: Disciplines of discourse (Vol. 1). Londres: Academic Press.

Villarroel, Gladys (2007). Las representaciones sociales: una nueva relación entre el individuo y la sociedad. Fermentum, 17(49), 434-454.

Wilson, Melvin, \& Cooney, Thomas (2002). Mathematics teacher change and development: The role of beliefs. En Gilah Leder, Erkki Pehkonen \& Günter Törner (Eds.), Beliefs: A hidden variable in mathematics education? (pp. 127-148). Dordrecht: Kluwer.

Woods, Peter (1987). La escuela por dentro: la etnografía en la investigación educativa. Barcelona: Paidós.

Woods, Devon (1996). Teacher cognition in language teaching: Beliefs, decision-making and classroom practice. Cambridge: Cambridge University Press. 